\title{
Clinical features of hypophosphatemic osteomalacia induced by long-term low-dose adefovir dipivoxil
}

This article was published in the following Dove Press journal: Drug Design, Development and Therapy

\author{
Sheng Zhu \\ Yu-Hui Yang \\ Rong-Wei Gao \\ Ran Li \\ Yu-Zhen Zou \\ Lei Feng \\ Bo Zhang
}

Department of Pharmacy, Peking Union Medical College Hospital, Chinese Academy of Medical Sciences and Peking Union Medical College, Beijing, People's Republic of China
Correspondence: Bo Zhang Department of Pharmacy, Peking Union Medical College Hospital, Chinese Academy of Medical Sciences and Peking Union Medical College, No I Shuaifuyuan, Wangfujing, Dongcheng District, Beijing 100730, People's Republic of China Tel +861069156513 Email zhangbopumch@163.com
Objective: To investigate the predictors of hypophosphatemic osteomalacia induced by adefovir dipivoxil (ADV) and to monitor for early detection.

Patients and methods: Hospitalized patients who were diagnosed with ADV-related hypophosphatemic osteomalacia were recruited and retrospectively analyzed in our hospital from January 2012 to December 2016. A telephone interview was conducted at 1, 3, 6, 9, 12, and 24 months after cessation of ADV.

Results: In the 8 patients enrolled in the study, the hypophosphatemic osteomalacia symptoms developed at an average of $5.14(4-7)$ years since ADV treatment $(10 \mathrm{mg} / \mathrm{d})$. The average alkaline phosphatase (ALP) level was 279.50 (137-548) U/L, which was significantly higher than the normal level (45-125 U/L). The serum phosphorus level was an average of 0.59 (0.43-0.69) $\mathrm{mmol} / \mathrm{L}$, which was lower than the normal range $(2.06-2.60 \mathrm{mmol} / \mathrm{L})$. Serum calcium levels of the enrolled patients remained within normal limits. Reduced estimated glomerular filtration rate (eGFR $\left.<29 \mathrm{~mL} / \mathrm{min} / 1.73 \mathrm{~m}^{2}\right)$ was seen in 4 cases. The clinical manifestations were mainly progressive systemic bone and joint pain, frequent fractures, trouble in walking, height reduction (4-6 cm), and so on. After cessation of ADV, symptoms like bone pain resolved gradually. Serum phosphorus level restored to normal in 4.5 months after the withdrawal of ADV. However, in 4 patients, renal function failed to return to normal in 24 months.

Conclusion: More attention should be paid to the duration of ADV treatment. The level of serum phosphorus and ALP, as well as renal function, should be monitored for early detection of potential adverse drug reactions.

Keywords: adefovir dipivoxil, hypophosphatemic osteomalacia, long term, follow-up, serum phosphate, renal tubular dysfunction

\section{Introduction}

Adefovir dipivoxil (ADV) is a single-phosphate adenosine nucleotide analogue, which is widely used for the treatment of chronic hepatitis B (CHB), especially in lamivudineresistant patients. ${ }^{1}$ A prospective study showed that dose-dependent renal toxicity is associated with ADV, and a low ADV dose of $10 \mathrm{mg} / \mathrm{d}$ is safe. ${ }^{2}$ However, in recent years, several cases have been reported showing that long-term application of low dose of ADV causes renal damage; ${ }^{3,4}$ the symptoms of renal damage include not only proteinuria but also hypophosphatemic osteomalacia. ${ }^{5}$ Adverse drug reactions of ADV are gaining increasing attention in recent years. The State Food and Drug Supervision and Administration has warned that prompt attention should be paid to the risk of ADV-induced hypophosphatemic osteomalacia. However, the corresponding symptoms do not appear in a short period of time, and the symptoms are often misdiagnosed as 
orthopedic diseases. ${ }^{6}$ This study attempts to explore the clinical features of hypophosphatemic osteomalacia induced by long-term use of low-dose ADV. A cross-sectional analysis was carried out on patients who had been diagnosed with ADV-induced hypophosphatemic osteomalacia in Peking Union Medical College Hospital in recent 5 years.

\section{Patients and methods}

\section{Study patients}

Participants in this cross-sectional study were recruited from Peking Union Medical College Hospital from January 2012 to December 2016 after reviewing their medical records. Of the 376 hospitalized patients who were diagnosed with hypophosphatemic osteomalacia, the following were excluded: those who were not using ADV; those with HIV or hepatitis C virus infection, metabolic cirrhosis, diabetes, bone metabolic disease, or chronic kidney disease; and those undergoing dialysis. Eight patients with confirmed diagnosis of ADV-induced hypophosphatemic osteomalacia were enrolled.

The study design was approved by the Peking Union Medical College Hospital Ethics Committee, and written informed consent was obtained from all the patients who were enrolled.

\section{Data collection}

The following clinical information of the 8 patients was recorded: gender; age; original disease and course of the disease; self-conscious symptom; drug application including the name and dosage of the drug, course of treatment, and drug withdrawal time; clinical manifestation; and laboratory examination results including alkaline phosphatase (ALP), serum creatinine, calcium, uric acid (UA), 24-hour urine phosphate, urine $\beta 2$-microglobulin, and so on. A telephone follow-up was conducted to record the prognosis of symptoms after $1,3,6,9,12$, and 24 months of discontinuation of ADV. The estimated glomerular filtration rate (eGFR) was calculated using the Chronic Kidney Disease Epidemiology Collaboration (CKD-EPI) formula: eGFR $\left(\mathrm{mL} / \mathrm{min} / 1.73 \mathrm{~m}^{2}\right)=194 \times$ age $^{-0.287} \times$ serum creatinine $(\mathrm{mg} / \mathrm{dL})^{-1.094}(\times 0.739$ if female $) .^{7}$

\section{Definition and criteria}

\section{Renal tubular dysfunction}

The renal tubular dysfunction can be evaluated based on eGFR as follows: normal, eGFR $\geq 90 \mathrm{~mL} / \mathrm{min} / 1.73 \mathrm{~m}^{2}$; mild renal impairment, 60-89 mL/min/1.73 $\mathrm{m}^{2}$; moderate renal impairment, 30-59 mL/min/1.73 m²; severe kidney damage, 15-29 $\mathrm{mL} / \mathrm{min} / 1.73 \mathrm{~m}^{2}$; and renal failure, $<15 \mathrm{~mL} / \mathrm{min} / 1.73 \mathrm{~m}^{2}$.

\section{Hypophosphatemia grading}

According to the level of blood phosphorus, hypophosphatemia can be sorted into mild, moderate, or severe as follows: normal, 0.81-1.45 mmol/L; mild hypophosphatemia, 0.60-0.81 mmol/L; moderate hypophosphatemia, 0.50-0.60 $\mathrm{mmol} / \mathrm{L}$; and severe hypophosphatemia, $<0.50 \mathrm{mmol} / \mathrm{L}^{8}{ }^{8}$

\section{Results \\ Patient characteristics}

Of the 8 patients, 6 were male and 2 female. The average age of patients was 55.00 (39-66) years, and all the 8 patients had cirrhosis, and took $10 \mathrm{mg} / \mathrm{d}$ ADV. The onset time of symptoms was an average of $5.14(4-7)$ years. Six patients were treated with ADV alone, while 2 received ADV combined with lamivudine (LAM) or entecavir (ETV), due to drug resistance or poor antiviral effect.

\section{Laboratory test}

The laboratory data of the 8 hospitalized patients who were diagnosed with ADV-induced hypophosphatemic osteomalacia before the drug withdrawal are presented in Table 1. The ALP level of the 8 cases was 279.50 (137-548) U/L, which was higher than the normal level (45-125 U/L). The serum phosphate level was an average of $0.59(0.43-0.69) \mathrm{mmol} / \mathrm{L}$, which was lower than the normal range $(0.81-1.45 \mathrm{mmol} / \mathrm{L})$. In one of the patients, the serum phosphate level was as low as $0.43 \mathrm{mmol} / \mathrm{L}$ (Table 2). Serum calcium remained within normal limits $(2.08-2.60 \mathrm{mmol} / \mathrm{L})$, except for one case in which the level was not checked. Based on eGFR calculated by the CKD-EPI equation, 4 cases were identified with moderate renal injuries and 2 with mild renal injuries (Table 3 ). In 3 patients, a significantly high level of $\beta 2$-microglobulin was detected in urine.

\section{Clinical manifestations}

All the 8 patients had bone pain and joint pain as chief complaint. Pain mainly occurred in the double side frame and double ankles, knees, hip joint, and lumbosacral portion; among the 8 patients, 3 suffered frequent fracture and 3 loss of weight and height $(4-6 \mathrm{~cm})$. Trouble in walking, swaying gait, limb weakness, and squatting difficulties were common clinical manifestations. The symptoms had lasted for 4 months to 4 years before they were admitted to hospital. The symptoms were misdiagnosed as orthopedic disease; in 2 cases, the symptoms were misdiagnosed as severe osteoporosis in other institutions, while in 1 case as lumbar disc herniation (Table 4). 
Table I Laboratory data of the 8 cases before the drug withdrawal

\begin{tabular}{|c|c|c|c|c|c|c|c|c|c|}
\hline$\overline{\text { Test }}$ & Normal range & Case I & Case 2 & Case 3 & Case 4 & Case 5 & Case 6 & Case 7 & $\overline{\text { Case } 8}$ \\
\hline ALP (U/L) & $45-125$ & 246 & 305 & 548 & 137 & 217 & 331 & 236 & 216 \\
\hline Serum phosphate $(\mathrm{mmol} / \mathrm{L})$ & $0.81-1.45$ & 0.58 & 0.69 & 0.59 & 0.59 & 0.43 & 0.56 & 0.56 & 0.73 \\
\hline Serum calcium (mmol/L) & $2.08-2.60$ & 2.4 & 2.44 & NG & 2.26 & 2.26 & 2.25 & 2.22 & 2.26 \\
\hline $25(\mathrm{OH}) \mathrm{D}_{3}(\mathrm{ng} / \mathrm{mL})$ & $8.0-50.0$ & 39.7 & NG & 11.5 & 290 & 11.2 & 13.5 & 9.8 & NG \\
\hline $\begin{array}{l}\text { Blood } \beta 2 \text {-microglobulin } \\
(\mathrm{mg} / \mathrm{L})\end{array}$ & $1.28-1.95$ & NG & 3.800 & NG & NG & NG & 3.5 & 3.62 & NG \\
\hline UA (mmol/L) & $210-430$ & 175 & 173 & NG & 132 & 126 & 80 & NG & NG \\
\hline eGFR $\left(\mathrm{mL} / \mathrm{min} / \mathrm{l} .73 \mathrm{~m}^{2}\right)$ & $>90$ & 57 & 76 & 65 & 52 & 48 & 63 & 55 & 80 \\
\hline $\mathrm{Cr}(\mu \mathrm{mol} / \mathrm{L})$ & $\begin{array}{l}\text { Male, 44-133; } \\
\text { female, 70-108 }\end{array}$ & 115 & 89 & 108 & 96 & 101 & 102 & 124 & 87 \\
\hline $\begin{array}{l}\text { 24-hour urine phosphate } \\
\text { (mmol/24 hours) }\end{array}$ & $23-48$ & 12.32 & $\mathrm{I} .4$ & 15.2 & 2,600 & NG & 23.4 & 8.10 & NG \\
\hline Urine $\beta 2$-microglobulin ( $\mathrm{mg} / \mathrm{L}$ ) & $0-0.2$ & 67.9 & $<0.225$ & 33.000 & NG & NG & NG & NG & NG \\
\hline
\end{tabular}

Abbreviations: ALP, alkaline phosphatase; UA, uric acid; eGFR, estimated glomerular filtration rate; Cr, serum creatinine; NG, not detected.

Table 2 Classifications of hypophosphatemia in the 8 cases with confirmed ADV-induced hypophosphatemic osteomalacia

\begin{tabular}{llll}
\hline Grading & $\begin{array}{l}\text { Serum phosphate } \\
(\mathbf{m m o l} / \mathrm{L})\end{array}$ & $\mathbf{N}$ & $\begin{array}{l}\text { Abnormal value, } \\
\text { median (range) }\end{array}$ \\
\hline Mild & $0.60-0.81$ & 2 & $0.69-0.73$ \\
Moderate & $0.50-0.60$ & 5 & $0.58(0.56-0.59)$ \\
Severe & $<0.50$ & $\mathrm{I}$ & 0.43 \\
\hline
\end{tabular}

Abbreviation: ADV, adefovir dipivoxil.

Table 3 Classifications of renal tubular dysfunction in the 8 cases with confirmed ADV-induced hypophosphatemic osteomalacia

\begin{tabular}{llll}
\hline Grading & $\begin{array}{l}\text { eGFR } \\
\left(\mathbf{m L} / \mathbf{m i n} / 1.73 \mathbf{~ m}^{2}\right)\end{array}$ & $\mathbf{N}$ & $\begin{array}{l}\text { Abnormal value, } \\
\text { median (range) }\end{array}$ \\
\hline Normal & $>90$ & 0 & NG \\
Mild & $60-89$ & 4 & $63-80$ \\
Moderate & $30-59$ & 4 & $48-57$ \\
Severe & $15-29$ & 0 & NG \\
Renal failure & $<15$ & 0 & NG
\end{tabular}

Abbreviations: ADV, adefovir dipivoxil; eGFR, estimated glomerular filtration rate; NG, not detected.

Table 4 Clinical manifestations of the 8 cases with confirmed ADV-induced hypophosphatemic osteomalacia

\begin{tabular}{lll}
\hline $\begin{array}{l}\text { Clinical } \\
\text { manifestations }\end{array}$ & N & Ratio (\%) \\
\hline Bone pain & 7 & 87.50 \\
Joint pain & 4 & 50.00 \\
Frequent fracture & 3 & 37.50 \\
Squatting difficulty & 3 & 37.50 \\
Weight loss & 3 & 37.50 \\
Height reduction & 3 & 37.50 \\
Trouble in walking & $\mathrm{I}$ & 12.50 \\
Limb weakness & $\mathrm{I}$ & 12.50 \\
Teeth loss & $\mathrm{I}$ & 12.50 \\
\hline
\end{tabular}

Abbreviation: ADV, adefovir dipivoxil.

\section{Therapeutic regimen adjustment}

ADV was discontinued after hypophosphatemic osteomalacia was detected. Antiviral regimens were changed to ETV $0.5 \mathrm{mg} / \mathrm{d}$, except in 1 case in which the regimen was changed to ETV $1 \mathrm{mg} / \mathrm{d}$. Two cases were treated with neutral phosphorus and calcitriol capsule. Regular monitoring of renal function and serum phosphate level was also carried out.

\section{Prognosis}

Eight patients were enrolled in our study of hypophosphatemia and renal tubular function after withdrawal of ADV. A telephone interview was conducted to record laboratory data and prognosis of the patients' symptoms after 1, 3, $6,9,12$, and 24 months of ADV discontinuation. One of the patients provided data only for the first month. During follow-up, there was a significant increase in virus level in 1 case 14 months after switching to ETV. Blood phosphorus level returned to normal in 4.5 (1-9) months after ADV withdrawal in the enrolled patients. eGFR returned to normal after 1 month in 2 cases, while in 4 patients renal function failed to return to normal in 24 months (Table 5).

\section{Discussion}

ADV plays a definite role in the treatment of CHB. ${ }^{9,10}$ Prospective studies have shown a dose-dependent nephrotoxicity is associated with ADV, and a low ADV dose of $10 \mathrm{mg} / \mathrm{d}$ is safe. ${ }^{2}$ However, in recent years, a growing number of cases have reported that renal impairment could be associated with low-dose, long-term application of ADV, which can be characterized by hypophosphatemic osteomalacia. ${ }^{11,12}$ Hypophosphatemic osteomalacia is a metabolic bone disease that leads to softening of the bones and can be caused by hypophosphatemia. The mechanism of this adverse drug reaction 
Table 5 Prognosis of the 8 cases after ADV discontinuation

\begin{tabular}{|c|c|c|c|c|c|c|c|c|c|c|c|c|c|c|c|c|c|c|}
\hline \multirow[t]{2}{*}{$\overline{\text { Test }}$} & \multicolumn{3}{|c|}{ I month } & \multicolumn{3}{|c|}{3 months } & \multicolumn{3}{|c|}{6 months } & \multicolumn{3}{|c|}{9 months } & \multicolumn{3}{|c|}{ I year } & \multicolumn{3}{|c|}{2 years } \\
\hline & 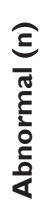 & 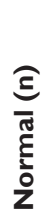 & 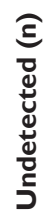 & 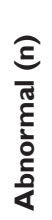 & 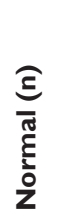 & 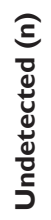 & 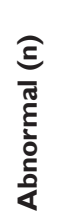 & 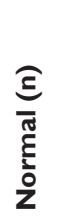 & 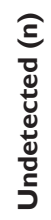 & 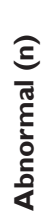 & $\begin{array}{l}\widehat{\Xi} \\
\overline{\text { ฮี }} \\
\text { है } \\
\text { z }\end{array}$ & 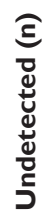 & $\begin{array}{l}\text { હે } \\
\overline{\text { ฮี }} \\
\text { है } \\
\frac{0}{0}\end{array}$ & $\begin{array}{l}\widehat{\Xi} \\
\overline{\text { ฮี }} \\
\text { है } \\
\text { z }\end{array}$ & 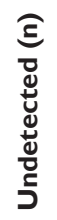 & 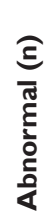 & $\begin{array}{l}\text { ఏે } \\
\text { ฮే } \\
\text { ż } \\
\text { z }\end{array}$ & 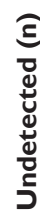 \\
\hline ALP & 4 & I & 3 & 3 & 0 & 3 & 4 & I & 3 & 3 & I & 4 & 4 & I & 3 & 4 & 2 & 2 \\
\hline Serum phosphate & 2 & 3 & 3 & 2 & I & 5 & 2 & 3 & 3 & I & 3 & 4 & 0 & 5 & 3 & 0 & 6 & 2 \\
\hline Serum calcium & 0 & 4 & 4 & 0 & 2 & 6 & 2 & 2 & 4 & 0 & 3 & 5 & 0 & 5 & 3 & I & 4 & 3 \\
\hline $25(\mathrm{OH}) \mathrm{D}_{3}$ & 0 & I & 7 & 0 & I & 7 & 0 & 2 & 6 & 0 & I & 7 & 0 & 2 & 6 & 0 & 1 & 7 \\
\hline Blood $\beta 2$-microglobulin & I & 0 & 7 & 0 & 0 & 8 & 0 & 0 & 8 & 0 & 0 & 8 & 0 & 0 & 8 & 0 & 0 & 8 \\
\hline UA & 3 & 0 & 5 & I & I & 6 & I & 2 & 5 & 0 & 2 & 6 & 2 & I & 4 & I & 2 & 5 \\
\hline eGFR & 4 & 2 & 2 & 4 & 0 & 4 & 4 & I & 3 & 4 & 0 & 4 & 4 & I & 3 & 4 & 2 & 2 \\
\hline 24-hour urine phosphate & 0 & 3 & 5 & 0 & 2 & 6 & 0 & 4 & 4 & 0 & 2 & 6 & 0 & 2 & 6 & 0 & 2 & 6 \\
\hline Urine $\beta 2$-microglobulin & 2 & 0 & 6 & 0 & 0 & 8 & 0 & 0 & 8 & 0 & 0 & 8 & 0 & 0 & 8 & 0 & 0 & 8 \\
\hline
\end{tabular}

Abbreviations: ADV, adefovir dipivoxil; ALP, alkaline phosphatase; UA, uric acid; eGFR, estimated glomerular filtration rate.

is unclear. Studies have shown that ADV mainly depends on renal tubular secretion. ADV has a strong affinity for human organic anion transporter-1 (hOAT-1) on the cellular plasma membrane ${ }^{13,14}$ Long-term or high-dose administration of ADV can result in increased drug concentration, mitochondrial DNA synthesis inhibition, cytochrome oxidase deficiency, mitochondrial function inhibition, and apoptosis of renal tubular epithelial cells. Therefore, renal tubular reabsorption capacity is weakened, and phosphorus and other elements in urine will be lost, leading to hypophosphatemic osteomalacia. Research has also shown this process may be associated with gene polymorphism of hOAT-1 and multidrug-resistant proteins (SLC22A6 and AVCC2 genotype). ${ }^{15}$

Among the 8 hospitalized patients, the number of male patients was greater than the female ( 6 male vs 2 female). Height and weight loss was seen in 3 osteomalacia patients. The severity of osteomalacia depends on the time to onset of symptoms. A previous study showed that the average duration of ADV treatment was 5 years, ${ }^{16}$ with the shorter time to onset of symptoms being 1.5 years and the longer time being 13 years since ADV treatment. In this research, the average time to onset of symptoms is 5.14 years, which is consistent with the literature results. At the beginning of the treatment, the patients were not prone to adverse reactions; as time went by, bone pain, joint pain, or fatigue appeared, but they were too mild to attract attention. Increased pain and walking disorders may easily be misdiagnosed as orthopedic diseases, and hence, they need more attention. In this study, 1 patient had bilateral ankle pain after taking ADV for 3 years, followed by knee pain a half year later, and developed pain in the hip 1 year later. By the time the pain was confirmed to be ADV-induced, the patient had taken
ADV for 6 years continuously, suggesting that ADV-induced hypophosphatemic osteomalacia may aggravate with time.

The ALP levels in 8 patients were higher than the normal range, while serum phosphorus values were lower than normal. It was reported that serum UA is associated with bone mass and bone turnover. ${ }^{17}$ Five of the 8 patients had taken the UA test during ADV therapy. The UA levels were much lower than the normal range. We used the CKD-EPI equation to calculate eGFR and evaluate renal impairment. Four cases were identified with moderate renal injuries, and 2 with mild renal injuries. In 3 patients, a significantly high level of $\beta 2$-microglobulin was detected in urine. It has been reported that $\beta 2$-microglobulin is detected clearly in patients with ADV-induced hypophosphatemic osteoporosis, and hence can be used as an indicator of renal function in these particular patients. ${ }^{18}$

Once the patients are diagnosed with ADV-induced hypophosphatemic osteomalacia, immediate dose adjustment or ADV withdrawal should be done. ${ }^{19}$ Neutral phosphorus, calcium, or vitamin D3 should be added to the treatment regimen if necessary. Symptoms of ADV-induced hypophosphatemic osteoporosis are reversible, and clinical manifestations such as bone pain, joint pain, and fatigue will gradually resolve. Patients could recover in a short period of time after ADV withdrawal. In this study, the patients received active treatment after diagnosis, and were subjected to regular monitoring of serum phosphorus and renal function. We found that after an average of 4.5 months, serum phosphorus level returned to normal. eGFR returned to normal after 1 month in 2 cases, while in 4 patients renal function failed to return to normal in 24 months, but the symptoms of bone pain and joint pain resolved completely. 
Clinical features of the 8 patients with hypophosphatemic osteomalacia induced by long-term low-dose ADV treatment are summarized in this study. The results suggest that patients undergoing long-term ADV treatment should be carefully monitored. ADV is widely used in clinic, but the associated long-term adverse reactions should be considered seriously. Those who take ADV should undergo regular testing of serum phosphorus and renal function; ${ }^{3,20}$ bone pain and muscle weakness should be seriously considered in these patients. We should pay more attention to the sex and age of drug users, as well as the duration of therapy. Adjustment of drug regimen should be considered timely if abnormal symptoms appear in these patients.

There are some limitations to our research that need to be addressed. It was a single-center and cross-sectional study, which did not have a large sample size and lacked the baseline data of patients before the initiation of ADV. Patients with multiple medical conditions from one of the biggest hospitals in the People's Republic of China were enrolled in this study. There are few such clinical reports to explore the risk factors and mechanisms of the adverse drug reactions. Further well-designed multicenter studies should be carried out on a larger-scale basis.

\section{Disclosure}

The authors report no conflicts of interest in this work.

\section{References}

1. Yundong Q, Qian Y, Lei W, et al. Clinical features and individualized treatment of 39 cases of adefovir dipivoxil-induced renal hypophosphatemia and osteomalacia. Chin J Infect Dis. 2015;33(11):678-681.

2. Izzedine $H$, Hulot JS, Launay-Vacher V, et al; Adefovir Dipivoxil International 437 Study Group; Adefovir Dipivoxil International 438 Study Group. Renal safety of adefovir dipivoxil in patients with chronic hepatitis B: two double-blind, randomized, placebo-controlled studies. Kidney Int. 2004;66(3):1153-1158.

3. Wang BF, Wang Y, Wang BY, Sun FR, Zhang D, Chen YS. Osteomalacia and Fanconi's syndrome caused by long-term low-dose adefovir dipivoxil. J Clin Pharm Ther. 2015;40(3):345-348.

4. Zou YZ, Hu Y, Zhang B. Fanconi's syndrome induced by adefovir: a case report and pooled analysis of 41 cases. Clin Med J. 2015;(2):68-73. Available from: http://d.wanfangdata.com.cn/periodical/lcywzlzz201502021. Accessed December 13, 2017.
5. Sobhonslidsuk A, Wanichanuwat J, Numthavaj P, et al. Nucleotide analogue-related proximal renal tubular dysfunction during long-term treatment of chronic hepatitis B: a cross-sectional study. Gastroenterol Res Pract. 2016;2016:2952635.

6. Shimizu M, Furusyo N, Ikezaki H, et al. Predictors of kidney tubular dysfunction induced by adefovir treatment for chronic hepatitis B. World J Gastroenterol. 2015;21(7):2116-2123.

7. Inker LA, Schmid CH, Tighiouart H, et al. Estimating glomerular filtration rate from serum creatinine and cystatin C. N Engl J Med. 2012; 367(1):20-29.

8. Yang X, Sun C, Yuan X. Clinical analysis in adefovir-induced low phosphorus in patients with chronic hepatitis B. Chin J Clin Hepatol. 2015;(12):2047-2050. Available from: http://caod.oriprobe.com/ articles/47306980/Clinical_analysis_of_hypophosphatemia_induced_ by_adefovir_dipivoxil_in.htm. Accessed December 13, 2017.

9. Liaw YF, Chu CM. Hepatitis B virus infection. Lancet. 2009;373(9663): 582-592.

10. Kahn J, Lagakos S, Wulfsohn M, et al. Efficacy and safety of adefovir dipivoxil with antiretroviral therapy: a randomized controlled trial. JAMA. 1999;282(24):2305-2312.

11. Wu C, Zhang H, Qian Y, Wang L, Gu X, Dai Z. Hypophosphatemic osteomalacia and renal Fanconi syndrome induced by low-dose adefovir dipivoxil: a case report and literature review suggesting ethnic predisposition. J Clin Pharm Ther. 2013;38(4):321-326.

12. Kim YJ, Cho HC, Sinn DH, et al. Frequency and risk factors of renal impairment during long-term adefovir dipivoxil treatment in chronic hepatitis B patients. J Gastroenterol Hepatol. 2012;27(2):306-312.

13. Ho ES, Lin DC, Mendel DB, Cihlar T. Cytotoxicity of antiviral nucleotides adefovir and cidofovir is induced by the expression of human renal organic anion transporter 1. J Am Soc Nephrol. 2000;11(3):383-393.

14. Tanji N, Tanji K, Kambham N, Markowitz GS, Bell A, D'agati VD. Adefovir nephrotoxicity: possible role of mitochondrial DNA depletion. Hum Pathol. 2001;32(7):734-740.

15. Wei Z, He JW, Fu WZ, Zhang ZL. Osteomalacia induced by longterm low-dose adefovir dipivoxil: clinical characteristics and genetic predictors. Bone. 2016;93:97-103.

16. Kim du H, Sung DH, Min YK. Hypophosphatemic osteomalacia induced by low-dose adefovir therapy: focus on manifestations in the skeletal system and literature review. J Bone Miner Metab. 2013;31(2): 240-246.

17. Ahn SH, Lee SH, Kim BJ, et al. Higher serum uric acid is associated with higher bone mass, lower bone turnover, and lower prevalence of vertebral fracture in healthy postmenopausal women. Osteoporos Int. 2013;24(12):2961-2970.

18. Takagi J, Morita H, Ito K, et al. Urinary $\beta$-2 microglobulin levels sensitively altered in an osteomalacia patient receiving add-on adefovir dipivoxil therapy for hepatitis B virus infection. Intern Med. 2016;55(12):1599-1603.

19. Jeong HJ, Lee JM, Lee TH, et al. Two cases of hypophosphatemic osteomalacia after long-term low dose adefovir therapy in chronic hepatitis B and literature review. J Bone Metab. 2014;21(1):76-83.

20. Lingyi K, Hui T. Report and analysis of Fanconi syndrome caused by low dose of adefovir dipivoxil in 5 cases. J Trop Dis Parasitol. 2016; 14(2):90-92.

\section{Publish your work in this journal}

Drug Design, Development and Therapy is an international, peerreviewed open-access journal that spans the spectrum of drug design and development through to clinical applications. Clinical outcomes, patient safety, and programs for the development and effective, safe, and sustained use of medicines are the features of the journal, which

\section{Dovepress}

has also been accepted for indexing on PubMed Central. The manuscript management system is completely online and includes a very quick and fair peer-review system, which is all easy to use. Visit http://www.dovepress.com/testimonials.php to read real quotes from published authors. 